\title{
ARE YOU PLEASED WITH YOUR NEIGHBORHOOD? A FUZZY COGNITIVE MAPPING-BASED APPROACH FOR MEASURING RESIDENTIAL NEIGHBORHOOD SATISFACTION IN URBAN COMMUNITIES
}

\author{
Fernando A. F. FERREIRA a,b,* \\ a ISCTE Business School, BRU-IUL, University Institute of Lisbon, Avenida das Forças Armadas, \\ 1649-026 Lisbon, Portugal \\ ${ }^{b}$ Fogelman College of Business and Economics, University of Memphis, Memphis, TN 38152-3120, USA
}

Received 14 September 2014; accepted 10 April 2015

\begin{abstract}
Previous research has indicated that residents' satisfaction with neighborhood conditions helps shape attitudes and has a high impact on residential valuations. This paper reports on research that sought to analyze the relationship between neighborhood characteristics and residents' degree of satisfaction. Based on the construction of a fuzzy cognitive map (FCM), which involved residents from several high- and low-quality neighborhoods in the Central-West region of Portugal, a framework that adds value to the way key determinants of neighborhood satisfaction are identified is proposed. Because FCMs allow the understanding of the cause-and-effect relationships between factors to be improved, this framework shows that for satisfaction with the neighborhood to increase, more attention needs to be paid to positive attitudes toward subjective variables that interfere with residents' satisfaction. The results presented can provide relevant information for the effective and efficient planning and development of residential environments. Strengths and weaknesses of this proposal are also discussed.
\end{abstract}

KEYWORDS: Determinants of neighborhood satisfaction; Problem structuring; Fuzzy cognitive mapping; Real estate strategic management

\section{INTRODUCTION}

In light of rapid world-wide industrialization and urbanization processes, the constructed landscape of places can add to, or subtract from, individuals' sense of satisfaction. It is widely known that deteriorated housing, low-quality neighborhoods, urban density and high crime rates, for example, can lead to increased social and psychological problems for residents (cf. Greenberg, Crossney 2007; Austin et al. 2012; Hipp et al. 2012; Honold et al. 2012; Kyttä et al. 2013). According to Bonaiuto et al. (2003: 42), this link is bi-directional, because residential and neighborhood satisfaction "encompasses cognitive, motivational and behavioural aspects, reflected in psychological correlates such as the tendency to give favourable evaluations of their dwelling place, improving it and their reluctance to leave it". Hence, sense of satisfaction influences residential choice and housing valuations, creating price volatility in the residential real estate

\footnotetext{
* Corresponding author. E-mail: fernando.alberto.ferreira@iscte.pt; fernando.ferreira@memphis.edu
}

market. In this sense, it has become increasingly important to evaluate neighborhood satisfaction for many reasons, and increasing interest has been shown toward the study of what people think of their neighborhood and how it affects their lives. In particular, neighborhood satisfaction, which broadly refers to residents' overall evaluation of their neighborhood habitat (cf. Hur et al. 2010), provides the basis for decisions about improvements in residential communities and about the design and development of future living environments, which is of prime concern for planners, policymakers, developers and city administrators (see Liu 1999; Amole 2009; Mohit et al. 2010; TeckHong 2012). Furthermore, among real estate hot topics, neighborhood satisfaction has been increasingly studied for the following reasons: (1) earlier research showed that neighborhood, as an intermediate level of analysis, serves as a link between "home" and "city" in people's perceptions of residential environments (Bonaiuto et al. 2003, 2006); 
(2) neighbors are commonly seen as an important community resource (Young et al. 2004); and (3) neighborhood satisfaction allows both objective and subjective aspects of residential quality to be considered, including "perceived environmental quality indicators [...] that can be extensively used in town-planning" (Bonaiuto et al. 2003: 42).

Following this, residential neighborhood satisfaction has been defined as "the experience of pleasure or gratification deriving from living in a specific place. [...] it is thus conceived as a multifaceted dimension" (Bonaiuto et al. 2006: 24). In this sense, notwithstanding the fact that many performance indicators have been proposed over the years, "the concept of satisfaction has become the most widely used in evaluating residential environments" (Amole 2009: 76). Unfortunately, most of the contributions presented so far "do not assess the truly important social processes and dynamics that result in cohesive and supportive neighborhoods" (Cantillon et al. 2003: 321). Simply put, "limitations of data and methodology as well as differences in substantive focus have meant that a number of unanswered questions remain" (Weden et al. 2008: 1257). Given the deep and intriguing relationship between neighborhood conditions and residents' satisfaction, this paper thus aims to analyze the relationship between neighborhood characteristics and residents' degree of satisfaction, examining the impact of the quality of local housing and neighborhood on residents' satisfaction. Specifically, grounded on a constructivist knowledge basis, the main purpose of this study is to use fuzzy cognitive mapping (FCM) to dynamically examine the influence of neighborhood conditions on urban residents' satisfaction. Beyond the reasons presented above, analyzing the determinants of neighborhood satisfaction is important "because the lack of neighborhood stability [and satisfaction] results in a paucity of high quality neighborhood institutions [...] which serve to bind residents together and provide services" (Cantillon et al. 2003: 322). Hence, there is considerable scope to explore the applicability of FCM in this particular context, namely because these maps allow cause-and-effect relationships between concepts to be better identified and decision situations to be better understood. Although this approach has long been validated and extensively applied in several decision situations, no previous evidence has been found applying FCM to this particular issue.

The remainder of the paper is organized as follows. The next section starts by presenting a brief review of the literature on neighborhood satisfaction. The following section presents the methodological background. Section 4 explains the technical steps followed during the construction of our framework and presents the results achieved. Section 5 presents concluding remarks and perspectives for future research.

\section{STUDIES ON NEIGHBORHOOD SATISFACTION}

Cho et al. (2005) claim that the last decades of rapid industrialization and urbanization have reduced the importance of neighborhoods and changed their meaning as traditional communities. Nevertheless, it is also true that we still spend a great deal of time and resources in our neighborhoods, making it important to understand how they are rated. Indeed, neighborhood satisfaction is recognized as an important component of individuals' quality of life and, thus, residents' evaluations of neighborhoods determine the way they respond to their habitat and form a basis for public policy feedback (cf. Greenberg, Crossney 2007; Salleh 2008).

Grounded on this initial premise, an array of different approaches to analyze residential environments has resulted from the efforts of different disciplines, namely: anthropology, architecture, economics, environmental design, geography, psychology and sociology (cf. Ge, Hokao 2006). Although applying and developing concepts intrinsically related to their theoretical foundations, these different approaches suggest that neighborhood satisfaction is a function of a whole series of factors, which have been analyzed from two main perspectives, namely: (1) the purposive approach, where neighborhood satisfaction is conceived as a measure of the degree to which the environment facilitates or inhibits the goal of the user; and (2) the aspiration-gap approach, where neighborhood satisfaction is seen as a measure of the gap between consumers actual and aspired needs (see Amole 2009; Fauzi et al. 2012).

It has been found, however, that "whenever residential satisfaction has been examined, it has usually focused on one (but rarely more than one) of the levels of the environment [...] and with very little differentiation between the levels" (Amole 2009: 77). In this sense, it is worth noting that a more comprehensive and robust view of this sense of residential and neighborhood satisfaction has been recently reported in the literature. Indeed, more and more researchers consider that neighborhood satisfaction should be conceptualized as a 
multi-faceted construct, comprising a wide range of different physical, social and management attributes, such as: relationships with neighbors; housing characteristics; and the local physical environment itself, which includes demographic factors, its functionality (e.g. safety, presence of and access to services), aesthetics (i.e. appearance) and health features (i.e. air quality and pollution) (cf. Bonaiuto et al. 2003, 2006; Amole 2009; Rioux, Werner 2011). Furthermore, "social and physical conditions of neighborhood and urban settings had been linked to both emotional and behavioral outcomes of neighborhood residents", meaning that the above mentioned determinants of neighborhood satisfaction involve cognitive, affective and conative dimensions (Austin et al. 2012: 419).

Specifically, in analyzing the effects of neighborhood conditions on residents' satisfaction, previous studies have analyzed many variables such as: local jurisdiction effect, crime, physical decay and other activities and land uses (Greenberg, Crossney 2007); noise, green areas, naturalness and openness (Bonaiuto et al. 2003; Gidlöf-Gunnarsson, Öhrström 2007; Hur et al. 2010; Jong et al. 2012); effects of place scale (Bonaiuto et al. 2003; Lewicka 2010); perceived neighborhood social cohesion, welfare, friendliness of neighbors, ethnic, racial and economic composition (Lansing, Marans 1969; Cheung, Leung 2011); architectural-planning space, landscaping, housing services, style and condition, children's playgrounds, community halls, organization, car parks, security and disability facilities, neighborhood facilities and environment (Lansing, Marans 1969; Bonaiuto et al. 2003; Salleh 2008; Youssoufi, Foltête 2013); communal services such as roads, transport services, sewer system and basic utilities within the housing area (Mohit, Azim 2012); and symbolic factors (e.g. sense of identity and prestige values) (Lansing, Marans 1969) (for further discussion, see also Zehner 1971; Türkoğlu 1997; Ukoha, Beamish 1997; Liu 1999; Westaway 2006; Stronegger et al. 2010; Rioux, Werner 2011; Gupta et al. 2012; Oshio, Urakawa 2012).

These contributions vary according to the focus of the investigation. Although satisfaction is commonly seen as an important indicator of quality of life and well-being (Amole 2009; Mohit, Azim 2012), helping to identify the relationships between various dimensions of the residential environment, it should be highlighted that very little is known about what predicts satisfaction in an urban community context overall. Indeed, "while conceptual and methodological improvements advanced theory and empirical support, the field is still struggling for a complete and adequate measure of community social organization", which can lead to higher indices of neighborhood satisfaction (Cantillon et al. 2003: 328). In this sense, following Cheung and Leung (2011: 570), "further research should ideally conduct both quantitative and qualitative studies to advance knowledge in various ways [...] Principally, the design is required to affirm causal relationships between the factors, typically by relying on a panel study". It is precisely to fill this gap that there is considerable scope to explore the applicability of fuzzy cognitive mapping in the context of this study, namely because its value relies in the elicitation and management of practical topics to compose a story about the relationships between determinants of neighborhood satisfaction.

\section{BACKGROUND ON FUZZY COGNITIVE MAPPING}

It is widely recognized that cognitive mapping is " $a$ useful tool for modelling the complex relationships among variables of a problem/phenomenon, even if complex" (Carlucci et al. 2013: 212). Although typically dependent on the participants' degree of involvement, cognitive maps "facilitate the representation and communication, support the identifcation and the interpretation of information, facilitate consultation and codification, and stimulate mental associations" (Gavrilova et al. 2013: 1758). This makes them very useful within decision making frameworks, allowing decision makers to deal with a simple and extremely versatile decision support tool. Indeed, cognitive maps boost discussion among decision makers, allowing the rate of omitted decision criteria to be reduced, and significantly improving the understanding of decision situations (cf. Ferreira et al. 2012).

Kosko $(1986 ; 1992)$ has been acknowledged for enhancing the power of this decision support tool and for introducing the term FCM, namely because he considered fuzzy values for the criteria and fuzzy degrees for the relationships between them (cf. Carlucci et al. 2013). After Kosko's pioneering work, FCM has been widely applied in different decision making contexts (e.g. Tsadiras et al. 2003; Kok 2009; Salmeron 2009, 2012; Yaman, Polat 2009; Papageorgiou et al. 2012; Ferreira, Jalali 2015). This type of cognitive map has two particular characteristics: (1) the relationships between nodes follow a fuzzy logic, meaning that causal relationships are simultaneously represented by a sign of positive/negative causality and by an inten- 


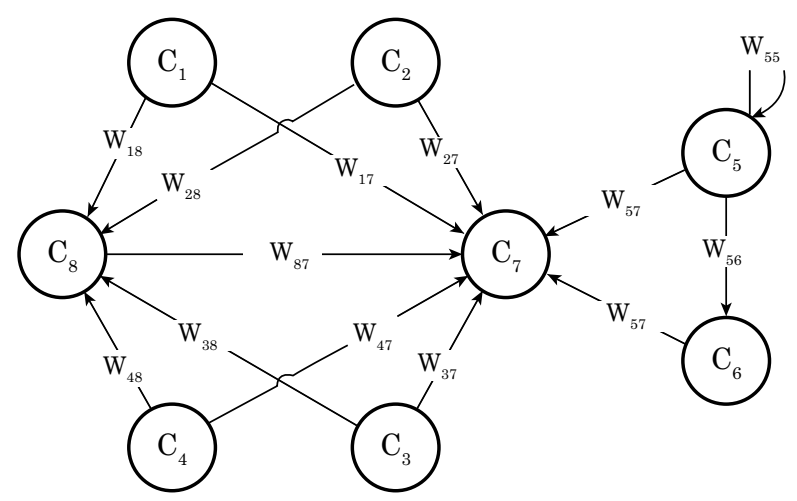

Fig. 1. Typical structure of an FCM (Salmeron 2012: 3706).

sity/influence degree number, which ranges from -1 to 1 ; and (2) the system incorporates ideas from artificial neural networks and fuzzy logic, involving feedback links among concepts/criteria, which allow temporal aspects to be dynamically considered in the decision making process (Carlucci et al. 2013; Carvalho 2013). Figure 1 illustrates the typical structure of an FCM, where $C_{i}$ represents criterion $i$ and $W i j$ stands for the influence degree of the relationship between criteria $i$ and $j$.

All the values in the map can be fuzzy. This means that each criterion has a state value $A_{i}$ that can be a fuzzy value in the range between $[0,1]$ or a bivalent logic in $\{0,1\}$. In addition, the weights of the links (also known as arcs) can be a fuzzy value within $[-1,1]$ or a trivalent logic within $\{-1$, $0,1\}$. In technical terms, this means that there are three different types of relationships between nodes: (1) negative causality $\left(W_{i j}<0\right)$, where an increase/decrease in the value of $C_{i}$ leads to an decrease/increase in the value of $C_{j}$; (2) null causality $\left(W_{i j}=0\right)$, which takes place when there is no relationship between $C_{i}$ and $C_{j}$; and (3) positive causality $\left(W_{i j}>0\right)$, where an increase/decrease in the value of $C_{i}$ leads to an increase/decrease in the value of $C_{j}$ (cf. Kim, Lee 1998; Mazlack 2009; Kok 2009; Salmeron 2009; Yaman, Polat 2009).

Behind the graphical representation, there is a $1 \times n$ state vector $A$ that gathers the values of the $n$ criteria; and a $n \times n$ weight matrix $W$ (i.e. connection matrix or adjacency matrix) that includes the weights $W_{i j}$ of the causal relationships. Kok (2009) and Carvalho (2013), among others, state that non-zero values on the main diagonal can be considered. However, this matrix usually presents all the entries in the main diagonal as equal to zero, meaning that a concept only seldom causes itself. Hence, the value of each node is influenced by the values of the interconnected nodes (with the appropriate weights) and by its previous value. The mathematics behind FCMs can be summarized in formulation (1), where $A_{i}{ }^{(t+1)}$ represents the activation level of criterion $C_{i}$ at time $t+1 ; f$ is a threshold activation function; $A_{i}^{(t)}$ stands for the activation level of criterion $C_{i}$ at time $t ; A_{j}{ }^{(t)}$ is the activation level of criterion $C_{j}$ at time $t$; and $W_{j i}$ represents the weight of the causal relationship between both criteria:

$$
A_{i}^{(t+1)}=f\left(A_{i}^{(t)}+\sum_{\substack{j \neq i \\ j=1}}^{n} A_{j}^{(t)} \cdot W_{j i}\right) .
$$

According to Mazlack (2009), the overall impact of a change in the value of one criterion can be given by a new state vector $A_{\text {new }}$, which is obtained by multiplying the previous state vector $A_{\text {old }}$ by the weight matrix $W$. As discussed by Carlucci et al. (2013: 213), "the resulting transformed vector is then repeatedly multiplied by the adjacency matrix and transformed until the system converges to a fixed point. Typically it converges in less than 30 simulation time steps". Figure 2 illustrates this
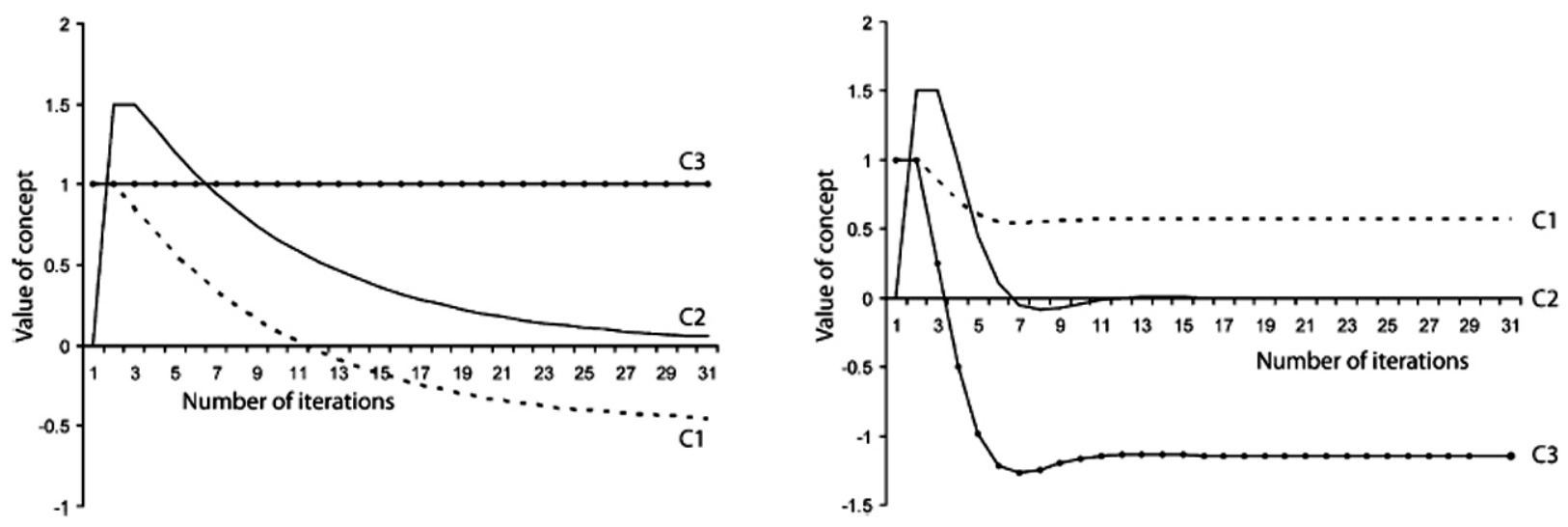

Fig. 2. FCM stabilization and value convergence points (Kok 2009: 125) 
exercise based on the results of an exemplificative simulation carried out by Kok (2009).

A ranking (i.e. "strength of impact") of concepts can then be obtained, showing how the system is perceived in the FCM. "What-if" questions can also be formulated, to ascertain the impact on the system as whole of changes in some concepts (Carvalho 2013). Overall, fuzzy cognitive mapping has "powerful and far-reaching consequences as a mathematical tool for modeling complex systems" (Mazlack 2009: 5). From this premise, there is considerable scope to explore its applicability in the identification of key determinants of neighborhood satisfaction. It is worth mentioning, however, that by enabling decision makers to consider their own values and preferences in the decision making process, without looking for optimum solutions, our proposal is quite distinct from "traditional" optimization methods using existing data. This is a reflection of the constructivist learning-based nature of the approach followed.

\section{CONSTRUCTING THE FUZZY COGNITIVE MAP}

In this section, the usefulness of fuzzy cognitive mapping in the construction of a measurement framework for neighborhood satisfaction is discussed. No previous documented evidence has been found reporting the application of this approach to evaluate residential neighborhood quality and satisfaction.

\subsection{Participants}

As far as the construction of a cognitive map is concerned, Yaman and Polat (2009: 387) defend that "using a group of experts has the benefit of improving the reliability of the final model". In this sense, when setting up a decision group, three basic guidelines were taken into consideration. Firstly, "the expert panel number is quite difficult to establish and no study has been conclusive with respect to it" (Salmeron 2009: 276). Secondly, caution was taken to form a group that could be brought together with some ease. Thirdly, it was taken into account that "the consultant [i.e. researcher or facilitator] will relate personally to a small number (say, three to ten persons)" (Eden, Ackermann 2001: 22). Grounded on these three basic guidelines, the experts were selected based on a voluntary basis and on the years of experience. This resulted in a group formed by six members (i.e. two women and four men with ages ranging between 31 and 73 years old, and with different academic backgrounds), which consisted mostly of representatives of homeowner associations and condominium administrators from different cities and neighborhoods of the Central-West region of Portugal. It is worth clarifying, however, that because our approach is process-oriented, the procedure followed can work well with a different group of decision makers and/or in different communities (cf. Ferreira et al. 2014). Methodologically, this also means that, with adjustments, this FCM-based framework is flexible enough to accommodate new information, and a major benefit is that it allows for greater transparency in the manner in which information is integrated and structured; which, in turn, allows for better informed and more comprehensive decision making. From this premise, there are no optimization concerns/routines during the construction of an FCM, and we recommend that the framework proposed be seen as a learning mechanism rather than as an end in itself or a tool to prescribe a single or final solution.

In this study, the group's FCM was constructed during an intensive 6-hour work session, which was conducted by a trained facilitator, accompanied by an ICT technician who was responsible for registering the session results. Due to the processoriented nature of the framework developed, it has been noted that the layout of the conferencing room can be important to potentiate group dynamics and to provide references for possible replications of the procedures followed (cf. Bana e Costa et al. 2014). The layout of the conferencing room used in this study is presented in Figure 3.

It is worth mentioning, in addition, that the panel members' origins were carefully selected according to parameters such as architectural and urban planning, human density and location, allowing different opinions to be confronted and analyzed. Furthermore, both high- and low-quality neighborhoods were considered within the urban context.

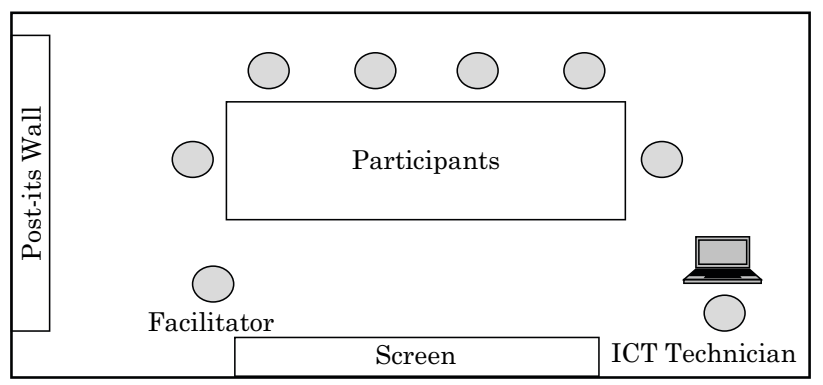

Fig. 3. Layout of the decision conferencing room (Adapted from Bana e Costa et al. 2014: 11) 


\subsection{Identifying concepts and quantifying relationships}

Lee et al. (2008: 61) defend that "neighborhood satisfaction is the complex perceptual construct of a person based on his/her objective and subjective environments and personal characteristics". With this premise in mind, the group meeting was initiated with a kick-off presentation of the session objectives and clarification of basic concepts related to FCMs, allowing misunderstandings to be avoided. Next, the panel members were asked the following trigger question: "Based on your own values and personal experience, what are the characteristics of a good neighborhood?", which provided the focus for debate and allowed the "post-its technique" to be applied.

According to Ackermann and Eden (2001), the basics of this technique consists of writing what the group members consider as important criteria on post-its (i.e. one criterion per post-it), and sticking those post-its on a large piece of paper. Based on permanent debate among the participants, this procedure should be repeated until the group reveals collective satisfaction with the number and depth of the criteria identified. The following phase of the technique consists in the organization of the post-its by areas of concern (i.e. clusters), allowing additional discussion to take place and, thus, clarification regarding the significance of each criterion to be increased. In the third and last stage of the process, each cluster is analyzed separately and the stickers are reorganized according to a meansend-based logic. Figure 4 presents two snapshots of the application of the "post-its technique" in this study.

The application of this technique is usually considered concluded when the group agrees on the form and content of the map, which is often called "strategic" map. In this study, the conception of the map was supported by the Decision Explorer soft- ware (www.banxia.com). Figure 5 presents the final outcome, which represents the group's consensus on the key determinants of neighborhood satisfaction (an editable version of the map can be obtained from the author upon request).

As recognized by Ferreira et al. (2014), the construction of a collective cognitive map assumes a subjective nature strongly dependent on the facilitator's skills and deeply influenced by the perceptions of the group. As such, it should be understood that the map represented in Figure 5 is "merely" an instrument meant to create consolidated information regarding the decision problem. While this may be identified as a methodological shortcoming, it is more than compensated by the efforts made by the participants involved in the decision process, and by the high volume of information discussed and contained in the map, which allow the decision problem to be clarified and the understanding of the relationships among criteria to be improved. Furthermore, the map created in this study allowed the participants to be provided with a holistic picture of neighborhood satisfaction, which they considered extremely positive.

At this stage of the process, the agreed upon collective map was reconstructed with the support of the FCMapper (http://www.fcmappers.net) and $P a$ jek software (http://pajek.imfm.si/doku.php), which allowed the participants to dynamically analyze the intensity of the links identified in Figure 5. Figure 6 presents the new layout of the map, where, for simplification reasons, the numbers stand for the determinants of neighborhood satisfaction previously identified (a full version using determinant names instead of numbers can be obtained from the author upon request).

The participants were provided with Figure 6 and, after additional discussion, they were asked to analyze the intensity of the relationships between criteria. The analysis carried out for one of the clusters is illustrated in Figure 7, where the
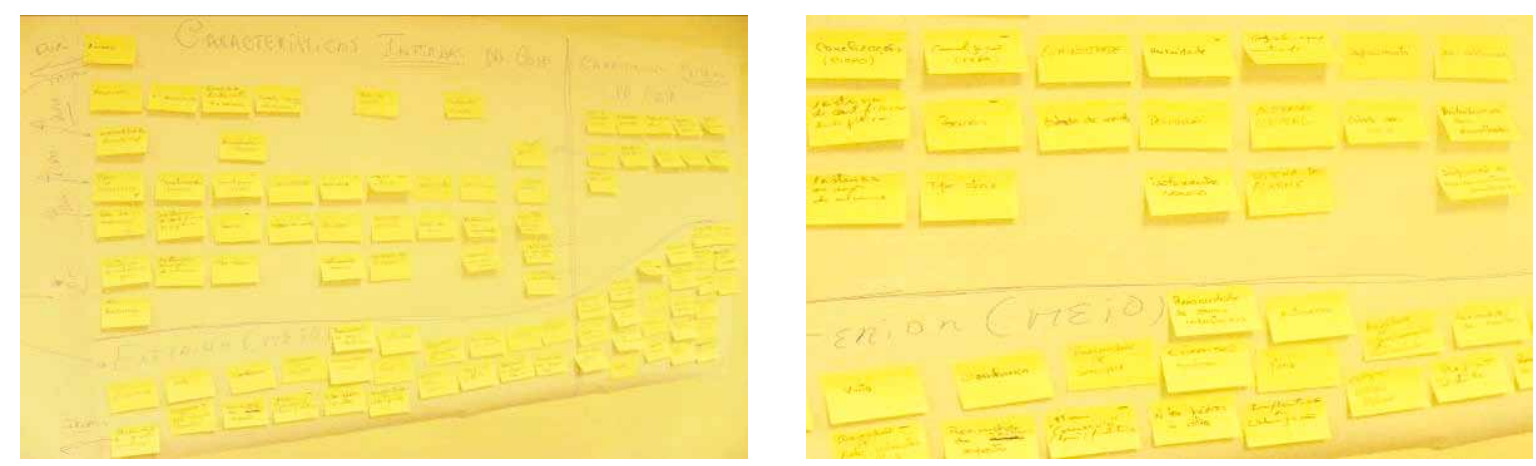

Fig. 4. Snapshots of the "post-its session" [ $3^{\text {rd }}$ stage] 


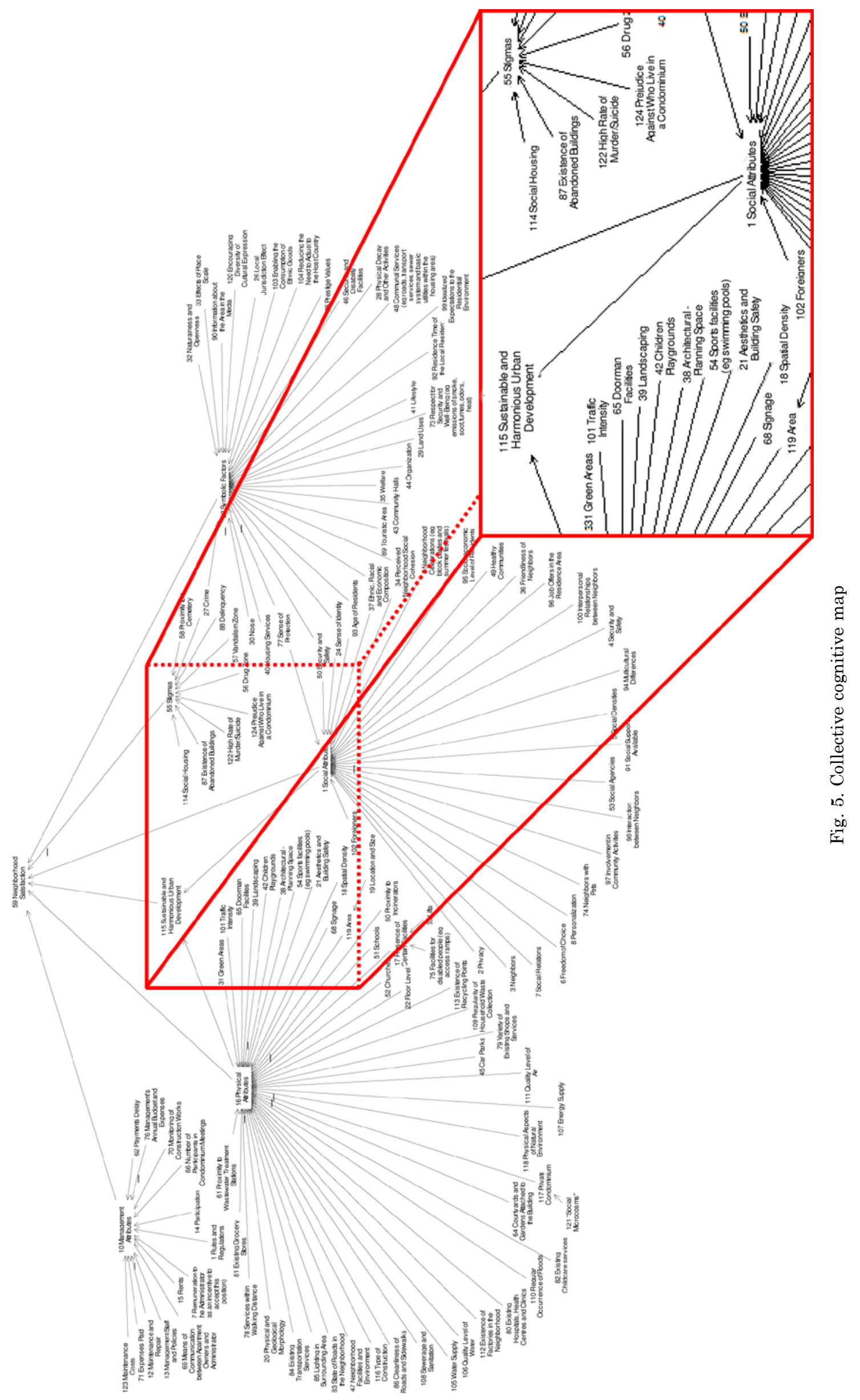




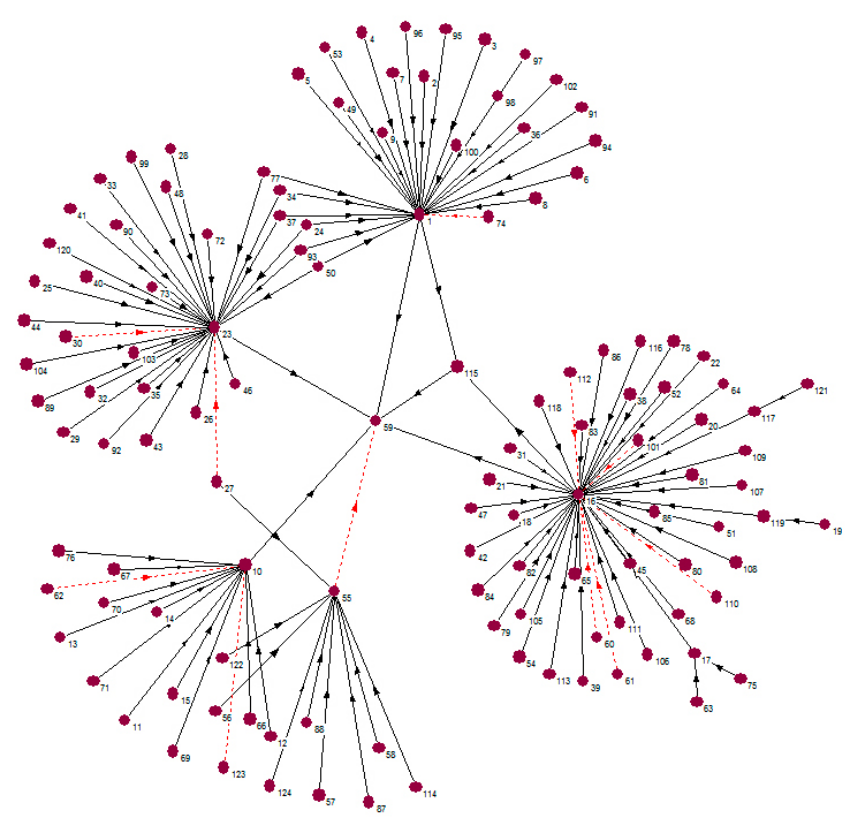

Fig. 6. [Initial] structure of the FCM

intensity of each cause-and-effect relationship is quantified and ranges from -1 to 1 , as indicated in section 3. It should be highlighted, however, that the analysis was extended to all the clusters.

As indicated in section 3 , the participants were asked to fill in an adjacency matrix containing the intensity degrees identified in the previous step. Due to the size of the final version of the map, which contains 124 interlinked determinants of neighborhood satisfaction, the resulting $124 \times 124$ weight matrix cannot be presented here. It should be underlined, however, that this procedure served to promote further debate on the research outputs and to determine the basis for recommendations (cf. Yaman, Polat 2009; Salmeron 2012; Carlucci et al. 2013).

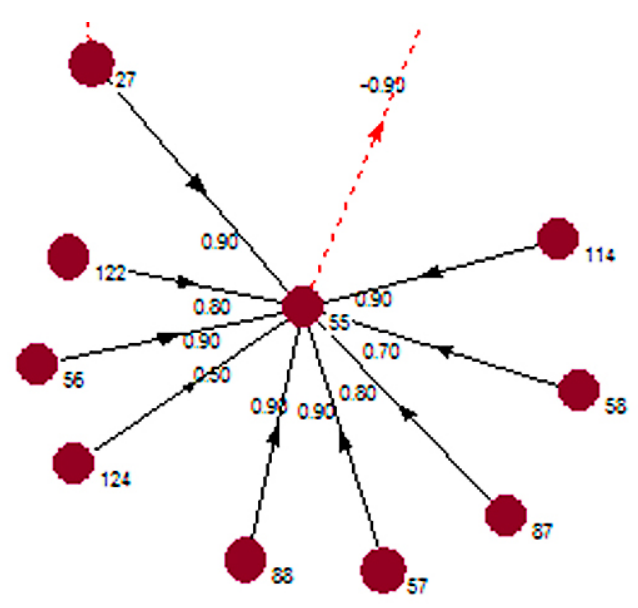

Fig. 7. Quantification of relationships

\subsection{Interpreting the research outputs}

The FCM obtained in this study was carefully analyzed and approved by the group members, representing the agreement reached by them. Due to the context-dependence of the map, it is important to bear in mind that rather than a single formulaic answer to the decision problem, the outputs obtained aim to encourage discussion among participants, while promoting a better understanding of the factors that influence neighborhood satisfaction. It is worth noting, in addition, that several static and dynamic tests were carried out throughout the study; and, "through a proper neural network computational model, [...] what we can get is an idea of the ranking of the variables in relationship to each other according to how the system is perceived in the FCM" (Carlucci et al. 2013: 216). In this sense, and following the mathematical formulations presented in section 3, Table 1 shows the most relevant determinants of neighborhood satisfaction that resulted from the concept interaction presented in the FCM.

As explained, the intensity of each link and the relative importance of each criterion are, indeed, calculated according to the experts' own perceptions of that importance and after discussion and negotiation among the panel members. We are aware that this approach is non-linear and inherently subjective. However, an important feature of the software used to support the process is that it allows interactive exploration of changes in the inputs to the model, such that the impact of such changes can be seen immediately, offering opportunities for further discussion. This also provides support for the estimates presented, which, as noted, resulted from the evolutionary collective perception that the group gained throughout the negotiation process. Again, this is a reflection of the constructivist nature of the framework.

Due to the high number of concepts comprised in the FCM (i.e. 124), only those with the highest

Table 1. Major determinants of neighborhood satisfaction [based on their intensity/centrality]

\begin{tabular}{lllll}
\hline Concepts & Reference & Outdegree & Indegree & Intensity \\
\hline $\begin{array}{l}\text { Physical } \\
\text { attributes }\end{array}$ & 16 & 1.80 & 28.40 & 30.20 \\
$\begin{array}{l}\text { Symbolic } \\
\text { factors }\end{array}$ & 23 & 0.80 & 21.90 & 22.70 \\
$\begin{array}{l}\text { Social } \\
\text { attributes }\end{array}$ & 1 & 1.60 & 17.70 & 19.30 \\
$\begin{array}{l}\text { Management } \\
\text { attributes }\end{array}$ & 10 & 0.80 & 9.10 & 9.90 \\
$\begin{array}{l}\text { Stigmas } \\
\text { Stigmat }\end{array}$ & 55 & 0.90 & 7.30 & 8.20 \\
\hline
\end{tabular}


intensity indices were included in Table 1. Still, it should be noted that all the determinants identified by the group have an intensity index. In the overall analysis of the intensity indices, it is worth highlighting that Physical Attributes, Symbolic Factors and Social Attributes seem to have a prominent role as driving forces of neighborhood satisfaction, considering their respective intensity indices of $30.20,22.70$ and 19.30 . These results seem to be consistent with the findings of a recent study developed by Bonaiuto et al. (2015), who highlight the importance of physical and social attributes in the assessment of neighborhood satisfaction. However, the FCM approach further identified a large number of other determinants (see Fig. 5), of which the focus of this study was on the ones with the highest levels of centrality (see Fig. 6 and Table 1). The issue of blight (i.e. abandoned buildings - reference 87 in Fig. 5), for instance, is one that can be easily overlooked and/or undetected by statistical methods alone, but can affect residential neighborhood satisfaction and property value. Indeed, as pointed out by the group, some of the factors included in the neuro-fuzzy system developed in this study are rarely taken into account in the current evaluation practices, but cognitive mapping allowed for their identification, reducing the rate of omitted factors (as recognized by the group members). Following this, the FCM conceived in this study offers a real insight into the determinants capable of improving neighborhood satisfaction, supporting the premise that "FCMs are simple, yet powerful tools for modeling and simulation of dynamic systems, based on domainspecific knowledge and experience" (Papageorgiou et al. 2012: 45).

This study is process-oriented, meaning that direct extrapolations of the results achieved should be treated with caution. While this can be seen as a methodological limitation, it also offers great potential in terms of flexibility and practical application. Indeed, as already pointed out by Salmeron (2009: 275), "from an Artificial Intelligence perspective, FCMs are supervised learning neural systems, whereas more and more data is available to model the problem, the system becomes better at adapting itself and reaching a solution". As such, this framework holds great potential for strategic planning and development of residential environments, which is of prime concern for architects, planners, developers, policymakers and city administrators.

\subsection{Limitations and recommendations}

The application of cognitive mapping techniques allowed the group members to: (1) identify key determinants of neighborhood satisfaction; (2) promote debate throughout the group meeting; (3) analyze and combine objective and subjective measures and attributes (for instance, some of the criteria identified in Figure 5 are purely objective (e.g. existence of children's playgrounds, green areas or basic utilities within the housing area), while others are more subjective (e.g. neighborhood interpersonal relationships)); and (4) provide insights about the driving forces and the key feedbacks in the system that can improve the understanding of neighborhood satisfaction.

Although the system created allowed encouraging results to be achieved, the methodological approach itself is not deprived of some limitations. It is limited in at least the following two ways. First, the technical procedures followed are subjective and context-dependent, meaning that direct extrapolations are discouraged without proper adjustments. Second (closely related to the first), "FCM development methods are far from being complete and well-defined, mainly because of the deficiencies that are present in the underlying theoretical framework [...] the development of FCM models almost always relies on human knowledge [... and] strongly depend on subjective beliefs of expert(s) from a given domain" (Stach et al. 2005: 372). It should be recalled, however, that these methodological shortcomings are more than compensated by the efforts made by the participants involved in the decision process, and by the high volume of information discussed, which allowed experiences to be shared and insights on the role of key relationships in the system to be detected, which might otherwise go undetected by statistical methods alone (for discussion, see Stach et al. 2010). Also, the FCM created in this study allowed cognitive load to be reduced, enhancing recall and learning of information. In addition, the importance of group dynamics and negotiation to clarify complex decision situations was recognized too, namely because they allowed participants to confront different opinions and perspectives, and to reach a consensual framework. Therefore, one can argue that the use of FCMs offers much more than a mere meeting of experts coming to some agreement. As recognized by Belton and Stewart (2002) and Ferreira et al. (2015), among others, the interactive nature of the approach allows decision makers to enter into decision dimensions that would not be possible to reach by other ways. All in all, as 
pointed out by Honold et al. (2012: 315), "enhancing the diversity of environmental data and integrating subjective perspectives of users [...] might be the most promising approach in defining priorities for intervention programs within urban areas".

\section{CONCLUSIONS}

According to Ge and Hokao (2006: 165), "the improvement of residential environment quality has become one of the main targets of city policy and urban planning". Hence, the results presented in this paper can provide relevant information for the effective and efficient planning and development of residential environments by assisting the better understanding of the various determinants of neighborhood satisfaction.

Although remarkable progress has been achieved over the years, the existing studies fall short of comprehensively identifying the dynamics behind the determinants of this phenomenon. In addition, it has long been acknowledged that the level of neighborhood satisfaction is specific to the housing area, community and city policies, which prevent the generalization of research findings (Mohit, Azim 2012). With these premises in mind, and assuming a non-dogmatic position, this study aimed to identify determinants of neighborhood satisfaction using FCMs. Because FCMs are known as neurofuzzy systems able to incorporate decision makers' knowledge and expertise, they reveal powerful and far-reaching consequences as a mathematical tool for analysis and modeling of complex decision situations (cf. Mazlack 2009). Hence, the FCM that resulted from this study allowed the participants to: (1) identify key factors/variables of neighborhood satisfaction; (2) boost discussion and negotiation throughout the group meeting; (3) analyze and combine different types of measures and attributes; and (4) provide important insights about the driving forces and respective key feedbacks that can improve the understanding of neighborhood satisfaction. In addition, the negotiation process allowed experiences to be shared and insights on the role of key relationships in the system to be detected, holding great potential in defining priorities for intervention programs within residential environments. Although still at an early stage, we believe that the approach proposed in this paper has proven worthwhile for multiple reasons. In particular, the findings presented have important implications for how researchers analyze neighborhood conditions. No evidence has been found of other studies attempting to analyze neighborhood satisfaction using FCM.
As discussed, this study is not without limitations. However, these limitations point to directions for future research. Indeed, such research could gauge the generality and specificity of the findings, and might want to: (1) conduct a panel study within a different geographical area; (2) incorporate lessons learnt through other studies with different participants and/or with different methodologies; (3) create a survey based on different panel studies to increase the reliability of the findings; and (4) contrast the strengths and weaknesses of this framework to other frameworks, approaches and/or methods. Following Bonaiuto et al. (2003), improvements will be seen as a step forward in furthering our knowledge of neighborhood evaluations, which can subsequently be compared and improved within environmental management strategies and interventions.

\section{ACKNOWLEDGMENTS}

The author wishes to thank the superb contribution and infinite willingness of the panel members: António Neves, Esmeraldo Monteiro, Hélio Jesus, Neuza Ferreira, Paula Gonçalves and Rui Monteiro. The author is also grateful to Professor Marjan Jalali for her comments in earlier drafts of this manuscript. Finally, the author gratefully acknowledges use of the services and facilities of the ISCTE Business School, University Institute of Lisbon, Portugal.

\section{REFERENCES}

Ackermann, F.; Eden, C. 2001. SODA - journey making and mapping in practice, in J. Rosenhead, J. Mingers (Eds.). Rational analysis for a problematic world revisited: problem structuring methods for complexity, uncertainty and conflict. $2^{\text {nd }}$ ed. Chichester: John Wiley \& Sons, 43-60.

Amole, D. 2009. Residential satisfaction in students' housing, Journal of Environmental Psychology 29(1): 76-85. http://dx.doi.org/10.1016/j.jenvp.2008.05.006

Austin, D.; Furr, L.; Spine, M. 2012. The effects of neighborhood conditions on perceptions of safety, Journal of Criminal Justice 30(5): 417-427. http://dx.doi. org/10.1016/S0047-2352(02)00148-4

Bana e Costa, C.; Lourenço, J.; Oliveira, M.; Bana e Costa, J. 2014. A socio-technical approach for group decision support in public strategic planning: the Pernambuco PPA case, Group Decision and Negotiation 23(1): 5-29. http://dx.doi.org/10.1007/s10726012-9326-2

Belton, V.; Stewart, T. 2002. Multiple criteria decision analysis: an integrated approach. Dordrecht: Kluwer Academic Publishers. http://dx.doi.org/10.1007/978-14615-1495-4 
Bonaiuto, M.; Fornara, F.; Ariccio, S.; Cancellieri, U.; Rahimi, L. 2015. Perceived residential environment quality indicators (PREQIs) relevance for UN-HABITAT city prosperity index (CPI), Habitat International 45(1): 53-63. http://dx.doi.org/10.1016/j.habitatint.2014.06.015

Bonaiuto, M.; Fornara, F.; Bonnes, M. 2003. Indexes of perceived residential environment quality and neighbourhood attachment in urban environments: a confirmation study on the city of Rome, Landscape and Urban Planning 65(1/2): 41-52. http://dx.doi. org/10.1016/S0169-2046(02)00236-0

Bonaiuto, M.; Fornara, F.; Bonnes, M. 2006. Perceived residential environment quality in middle- and low-extension Italian cities, Revue Européenne de Psychologie Appliquée 56(1): 23-34. http://dx.doi. org/10.1016/j.erap.2005.02.011

Cantillon, D.; Davidson, W.; Schweitzer, J. 2003. Measuring community social organization: sense of community as a mediator in social disorganization theory, Journal of Criminal Justice 31(4): 321-339. http://dx.doi.org/10.1016/S0047-2352(03)00026-6

Carlucci, D.; Schiuma, G.; Gavrilova, T.; Linzalone, R. 2013. A fuzzy cognitive map based approach to disclose value creation dynamics of ABIs, in Proceedings of the 8th International Forum on Knowledge Asset Dynamics (IFKAD-2013), 12-14 June 2013, Zagreb, Croatia, 207-219.

Carvalho, J. 2013. On the semantics and the use of fuzzy cognitive maps and dynamic cognitive maps in social sciences, Fuzzy Sets and Systems 214: 6-19. http:// dx.doi.org/10.1016/j.fss.2011.12.009

Cheung, C.; Leung, K. 2011. Neighborhood homogeneity and cohesion in sustainable community development, Habitat International 35(4): 564-572. http:// dx.doi.org/10.1016/j.habitatint.2011.03.004

Cho, Y.; Park, G.; Echevarria-Cruz, S. 2005. Perceived neighborhood characteristics and the health of adult Koreans, Social Science \& Medicine 60(6): 1285-1297. http://dx.doi.org/10.1016/j.socscimed.2004.06.054

Eden, C.; Ackermann, F. 2001. SODA - the principles, in J. Rosenhead, J. Mingers (Eds.). Rational analysis for a problematic world revisited: problem structuring methods for complexity, uncertainty and conflict. $2^{\text {nd }}$ ed. Chichester: John Wiley \& Sons, 21-41.

Fauzi, S.; Yusof, N.; Abidin, N. 2012. The relationship of housing defects, occupants' satisfaction and loyalty behavior in build-then-sell houses, Procedia - Social and Behavioral Sciences 62: 75-86. http://dx.doi. org/10.1016/j.sbspro.2012.09.014

Ferreira, F.; Jalali, M. 2015. Identifying key determinants of housing sales and time-on-the-market (TOM) using fuzzy cognitive mapping, International Journal of Strategic Property Management 19(3): 235-244. http://dx.doi.org/10.3846/1648715X.2015.1052587

Ferreira, F.; Jalali, M.; Meidutè-Kavaliauskienè, I.; Viana, B. 2015. A metacognitive decision making based-approach to bank customer loyalty measurement and management, Technological and Economic Development of Economy 21(2): 280-300. http:// dx.doi.org/10.3846/20294913.2014.981764

Ferreira, F.; Santos, S.; Rodrigues, P.; Spahr, R. 2014. Evaluating retail banking service quality and convenience with MCDA techniques: a case study at the bank branch level, Journal of Business Economics and Management 15(1): 1-21. http://dx.doi.org/10.38 46/16111699.2012.673504

Ferreira, F.; Spahr, R.; Santos, S.; Rodrigues, P. 2012. A multiple criteria framework to evaluate bank branch potential attractiveness, International Journal of Strategic Property Management 16(3): 254-276. http://dx.doi.org/10.3846/1648715X.2012.707629

Gavrilova, T.; Carlucci, D.; Schiuma, G. 2013. Art of visual thinking for smart business education, in Proceedings of the 8th International Forum on Knowledge Asset Dynamics (IFKAD-2013), 12-14 June 2013, Zagreb, Croatia, 1754-1761.

Ge, J.; Hokao, K. 2006. Research on residential lifestyles in Japanese cities from the viewpoints of residential preference, residential choice and residential satisfaction, Landscape and Urban Planning 78(3): 165-178. http://dx.doi.org/10.1016/j.landurbplan.2005.07.004

Gidlöf-Gunnarsson, A.; Öhrström, E. 2007. Noise and well-being in urban residential environments: the potential role of perceived availability to nearby green areas, Landscape and Urban Planning 83(2): 115-126. http://dx.doi.org/10.1016/j.landurbplan.2007.03.003

Greenberg, M.; Crossney, K. 2007. Perceived neighborhood quality in the United States: measuring outdoor, housing and jurisdictional influences, SocioEconomic Planning Sciences 41(3): 181-194. http:// dx.doi.org/10.1016/j.seps.2005.10.005

Gupta, K.; Kumar, P.; Pathan, S.; Sharma, K. 2012. Urban neighborhood green index: a measure of green spaces in urban areas, Landscape and Urban Planning 105(3): 325-335. http://dx.doi.org/10.1016/j.landurbplan.2012.01.003

Hipp, J.; Faris, R.; Boessen, A. 2012. Measuring 'neighborhood': constructing network neighborhoods, Social Networks 34(1): 128-140. http://dx.doi.org/10.1016/j. socnet.2011.05.002

Honold, J.; Beyer, R.; Lakes, T.; Meer, E. 2012. Multiple environmental burdens and neighborhood-related health of city residents, Journal of Environmental Psychology 32(4): 305-317. http://dx.doi.org/10.1016/j. jenvp.2012.05.002

Hur, M.; Nasar, J.; Chun, B. 2010. Neighborhood satisfaction, physical and perceived naturalness and openness, Journal of Environmental Psychology 30(1): 52-59. http://dx.doi.org/10.1016/j.jenvp.2009.05.005

Jong, K.; Albin, M.; Skärbäck, E.; Grahn, P.; Björk, J. 2012. Perceived green qualities were associated with neighborhood satisfaction, physical activity, and general health: results from a cross-sectional study in suburban and rural Scania, southern Sweden, Health \& Place 18(6): 1374-1380. http://dx.doi.org/10.1016/j. healthplace.2012.07.001

Kim, H.; Lee, K. 1998. Fuzzy implications of fuzzy cognitive map with emphasis on fuzzy causal relationship and fuzzy partially causal relationship, Fuzzy Sets and Systems 97(3): 303-313. http://dx.doi. org/10.1016/S0165-0114(96)00349-1

Kok, K. 2009. The potential of fuzzy cognitive maps for semi-quantitative scenario development, with an example from Brazil, Global Environmental Change 19(1): 122-133. http://dx.doi.org/10.1016/S01650114(96)00349-1 
Kosko, B. 1986. Fuzzy cognitive maps, International Journal of Man-Machine Studies 24(1): 65-75. http:// dx.doi.org/10.1016/S0020-7373(86)80040-2

Kosko, B. 1992. Neural networks and fuzzy systems. New Jersey: Prentice-Hall.

Kyttä, M.; Broberg, A.; Tzoulas, T.; Snabb, K. 2013. Towards contextually sensitive urban densification: location-based soft GIS knowledge revealing perceived residential environmental quality, Landscape and Urban Planning 113: 30-46. http://dx.doi. org/10.1016/j.landurbplan.2013.01.008

Lansing, J.; Marans, R. 1969. Evaluation of neighborhood quality, Journal of the American Institute of Planners 35(3): 195-199. http://dx.doi. org/10.1080/01944366908977953

Lee, S.; Ellis, C.; Kweon, B.; Hong, S. 2008. Relationship between landscape structure and neighborhood satisfaction in urbanized areas, Landscape and Urban Planning 85(1): 60-70. http://dx.doi.org/10.1016/j.landurbplan.2007.09.013

Lewicka, M. 2010. What makes neighborhood different from home and city? Effects of place scale on place attachment, Journal of Environmental Psychology 30(1): 35-51. http://dx.doi.org/10.1016/j.jenvp.2009.05.004

Liu, A. 1999. Residential satisfaction in housing estates: a Hong Kong perspective, Automation in Construction 8(4): 511-524. http://dx.doi.org/10.1016/S09265805(98)00098-3

Mazlack, L. 2009. Representing causality using fuzzy cognitive maps, in Proceedings of the Annual Meeting of the North American Fuzzy Information Processing Society (NAFIPS-2009), 14-17 June 2009, Cincinnati, Ohio, USA, 1-6. http://dx.doi.org/10.1109/ nafips.2009.5156434

Mohit, M.; Azim, M. 2012. Assessment of residential satisfaction with public housing in Hulhumale', Maldives, Procedia - Social and Behavioral Sciences 50: 756-770. http://dx.doi.org/10.1016/j.sbspro.2012.08.078

Mohit, M.; Ibrahim, M.; Rashid, Y. 2010. Assessment of residential satisfaction in newly designed public lowcost housing in Kuala Lumpur, Malaysia, Habitat International 34(1): 18-27. http://dx.doi.org/10.1016/j. habitatint.2009.04.002

Oshio, T.; Urakawa, K. 2012. Neighbourhood satisfaction, self-rated health, and psychological attributes: a multilevel analysis in Japan, Journal of Environmental Psychology 32(4): 410-417. http://dx.doi. org/10.1016/j.jenvp.2012.07.003

Papageorgiou, E.; Roo, J.; Huszka, C.; Colaert, D. 2012. Formalization of treatment guidelines using fuzzy cognitive maps and semantic web tools, Journal of Biomedical Informatics 45(1): 45-60. http://dx.doi. org/10.1016/j.jbi.2011.08.018

Rioux, L.; Werner, C. 2011. Residential satisfaction among aging people living in place, Journal of Environmental Psychology 31(2): 158-169. http://dx.doi. org/10.1016/j.jenvp.2010.12.001

Salleh, A. 2008. Neighbourhood factors in private lowcost housing in Malaysia, Habitat International 32(4): 485-493. http://dx.doi.org/10.1016/j.habitatint.2008.01.002

Salmeron, J. 2009. Augmented fuzzy cognitive maps for modelling LMS critical success factors, Knowl-
edge-Based Systems 22(4): 275-278. http://dx.doi. org/10.1016/j.knosys.2009.01.002

Salmeron, J. 2012. Fuzzy cognitive maps for artificial emotions forecasting, Applied Soft Computing 12(12): 3704-3710. http://dx.doi.org/10.1016/j. asoc.2012.01.015

Stach, W.; Kurgan, L.; Pedrycz, W. 2010. A divide and conquer method for learning large fuzzy cognitive maps, Fuzzy Sets and Systems 161(19): 2515-2532. http://dx.doi.org/10.1016/j.fss.2005.01.009

Stach, W.; Kurgan, L.; Pedrycz, W.; Reformat, M. 2005. Genetic learning of fuzzy cognitive maps, Fuzzy Sets and Systems 153(3): 371-401. http://dx.doi. org/10.1016/j.fss.2005.01.009

Stronegger, W.; Titze, S.; Oja, P. 2010. Perceived characteristics of the neighborhood and its association with physical activity behavior and self-rated health, Health \& Place 16(4): 736-743. tp://dx.doi. org/10.1016/j.healthplace.2010.03.005

Teck-Hong, T. 2012. Housing satisfaction in medium- and high-cost housing: the case of greater Kuala Lumpur, Malaysia, Habitat International 36(1): 108-116. http://dx.doi.org/10.1016/j.habitatint.2011.06.003

Tsadiras, A.; Kouskouvelis, I.; Margaritis, K. 2003. Using fuzzy cognitive maps as a decision support system for political decisions, in Proceedings of the 8th Panhellenic Conference on Informatics (PCI-2001), 8-10 November 2001, Nicosia, Cyprus, 172-182. http://dx.doi.org/10.1007/3-540-38076-0_12

Türkoğlu, H. 1997. Residents' satisfaction of housing environments: the case of Istanbul, Turkey, Landscape and Urban Planning 39(1): 55-67. http://dx.doi. org/10.1016/S0169-2046(97)00040-6

Ukoha, O.; Beamish, J. 1997. Assessment of residents' satisfaction with public housing in Abuja, Nigeria, Habitat International 21(4): 445-460. http://dx.doi. org/10.1016/S0197-3975(97)00017-9

Weden, M.; Carpiano, R.; Robert, S. 2008. Subjective and objective neighborhood characteristics and adult health, Social Science \& Medicine 66(6): 1256-1270. http://dx.doi.org/10.1016/j.socscimed.2007.11.041

Westaway, M. 2006. A longitudinal investigation of satisfaction with personal and environmental quality of life in an informal South African housing settlement, Doornkop, Soweto, Habitat International 30(1): 175189. http://dx.doi.org/10.1016/j.habitatint.2004.09.003

Yaman, D.; Polat, S. 2009. A fuzzy cognitive map approach for effect-based operations: an illustrative case, Information Sciences 179(4): 382-403. http:// dx.doi.org/10.1016/j.ins.2008.10.013

Young, A.; Russell, A.; Powers, J. 2004. The sense of belonging to a neighbourhood: can it be measured and is it related to health and well being in older women?, Social Science \& Medicine 59(12): 2627-2637. http://dx.doi.org/10.1016/j.socscimed.2004.05.001

Youssoufi, S.; Foltête, J. 2013. Determining appropriate neighborhood shapes and sizes for modeling landscape satisfaction, Landscape and Urban Planning 110: 12-24. http://dx.doi.org/10.1016/j.landurbplan.2012.09.005

Zehner, R. 1971. Neighborhood and community satisfaction in new towns and less planned suburbs, Journal of the American Institute of Planners 37(6): 379-385. http://dx.doi.org/10.1080/01944367108977387 